\title{
Retrospective analysis of the clinical course of patients treated for polymyalgia
}

This article was published in the following Dove Press journal:

Open Access Rheumatology: Research and Reviews

24 April 2013

Number of times this article has been viewed

\author{
Dung Do-Nguyen' \\ Charles A Inderjeeth ${ }^{1-3}$ \\ Jack Edelman ${ }^{2}$ \\ Patrick Cheah ${ }^{2}$
}

'Rehabilitation and Aged Care, North Metropolitan Health Service,

${ }^{2}$ Department of Rheumatology,

Sir Charles Gairdner Hospital,

${ }^{3}$ Faculty of Medicine and

Pharmacology, The University of Western Australia, Perth,

WA, Australia
Correspondence: Charles A Inderjeeth Department of Rehabilitation and Aged Care, Sir Charles Gairdner Hospital, Hospital Avenue, Nedlands, Western Australia 6009, Australia

Tel $+6 \mid 0893463660$

Fax +610893462811

Email charles.inderjeeth@health.wa.gov.au
Background: Polymyalgia rheumatica is a chronic inflammatory rheumatic condition, for which the mainstay of treatment is corticosteroids. Here, we review the clinical course of treated patients initially presenting with polymyalgic symptoms.

Methods: A retrospective audit was performed of patients who presented with a possible diagnosis of polymyalgia rheumatica. Biochemical markers and prednisone doses were assessed at the initial review, at one month, and 3, 6, and 12 months later.

Results: A cohort of 135 patients was identified, comprising 91 females and 44 males of mean age 70.7 years. All patients were treated with oral prednisone at an initial mean dose of $21.3 \mathrm{mg}$. Mean baseline C-reactive protein level and erythrocyte sedimentation rate were $41.6 \mathrm{mg} / \mathrm{L}$ and $48.6 \mathrm{~mm} /$ hour, respectively. Following initiation of therapy, there was a dramatic and sustained decrease in both inflammatory markers. A clinical response was observed in $96.2 \%$ of patients, but remission was achieved in only $18.2 \%$. Of those initially diagnosed with polymyalgia rheumatica, $24.8 \%$ were subsequently diagnosed with a different rheumatic condition.

Conclusion: The excellent response rate to corticosteroid therapy is well established in the literature, but in this research, remission rates were comparatively low during the 12-month study period. The current value of disease-modifying antirheumatic drugs and biologic therapy appears uncertain, and further trials to establish their precise role would be beneficial. A large portion of patients presenting with polymyalgia were eventually diagnosed to have another rheumatic disease, thus reflecting the broad differential diagnosis of polymyalgia symptoms. Polymyalgia symptoms can occur in patients with polymyalgia rheumatica and other rheumatic conditions. This group has a good response to prednisone therapy, although remission at 12 months appears to be uncommon. The gold standard of treatment remains corticosteroid therapy.

Keywords: polymyalgia rheumatica, diagnosis, treatment

\section{Introduction}

Polymyalgia rheumatica (PMR) is a chronic inflammatory rheumatic condition affecting the elderly. ${ }^{1}$ It is characterized clinically by aching and morning stiffness of the shoulder and pelvic girdles. The incidence is $20-50$ per year per 100,000 people, and increases with age, with a female preponderance of approximately two to one. ${ }^{1-3}$

The etiology of PMR is not known, although it is thought that there is a genetic component, with studies showing associations with specific alleles of HLA-DR4., ${ }^{2,4}$ Proposed environmental triggers have included viral or other infectious organisms, and although inconclusive, studies have shown an increased prevalence of antibodies to respiratory syncytial virus and adenovirus in patients with PMR. ${ }^{5}$ The pathological findings of PMR suggest a mild synovitis characterized by CD4+ T lymphocytes as 
well as subclinical arterial inflammation, with the presence of activated dendritic cells, interleukin-1, and interleukin-6. ${ }^{6,7}$

PMR is associated with temporal arteritis, also known as giant cell arteritis. It is thought that PMR and giant cell arteritis have the same underlying pathological basis and represent different spectra of the same disease process. ${ }^{1,8}$ In those diagnosed with PMR, up to $20 \%$ go on to develop giant cell arteritis during the course of their disease, whilst up to $90 \%$ of patients with giant cell arteritis will have polymyalgic symptoms. ${ }^{2}$

Diagnosis of PMR can be difficult and a challenge for clinicians because of overlap of symptoms with other rheumatic conditions and a vast differential diagnosis. Various guidelines exist to aid the diagnosis of PMR, with most criteria including age over 50 years, symmetrical aching of the shoulder and/or pelvic girdles, morning stiffness lasting over 45 minutes, and biochemical evidence of elevated acutephase reactants. ${ }^{1,2,8}$ Another criterion that has been used is a rapid response to corticosteroid therapy., ${ }^{2,9,10}$ Other clinical features may include tenosynovitis and edematous swelling of the hands, wrists, and ankles, and constitutional symptoms of fevers, fatigue, anorexia, weight loss, and depression. ${ }^{1,3,9,10}$

Laboratory findings include elevated acute-phase reactants, including C-reactive protein and erythrocyte sedimentation rate, as well as normocytic anemia. Antinuclear antibodies, rheumatoid factor, and anticyclic citrullinated protein antibodies are typically normal. ${ }^{11}$ Although magnetic resonance imaging and ultrasound may show extra-articular synovitis and bursal effusion, their clinical significance is yet to be established. ${ }^{12-15}$

The mainstay of treatment for PMR is corticosteroids, most commonly oral prednisone. Guidelines propose a starting prednisone dose of $15-25 \mathrm{mg}$, with gradual tapering. ${ }^{16-18}$ Many patients require long-term steroid therapy, and relapse and remission of PMR is not uncommon during the course of the disease. ${ }^{17,18}$ Consequently, patients are at risk of developing steroid-related side effects, including diabetes mellitus, infections, psychosis, cataracts, and skin changes. Furthermore, because PMR mainly affects the elderly, a common issue encountered is steroid-induced osteoporosis. There is evidence to suggest that bone turnover is also increased as a result of PMR itself, independent of the steroid burden. ${ }^{19}$ This reinforces the importance of osteoporosis screening and prophylactic treatment in those with newly diagnosed PMR. In addition to minimizing steroid-associated complications, other forms of treatment, such as disease-modifying antirheumatic drugs (DMARDs) have been coprescribed as steroid-sparing therapy, but with mixed results. ${ }^{10,17,18,20}$
Here we review the clinical course of treated patients initially presenting with polymyalgic symptoms, including development of other rheumatic conditions. We also review the clinical and biochemical response to steroid therapy, use of DMARDs as steroid-sparing therapy, and rates of remission during a 12-month follow-up period.

\section{Materials and methods}

We undertook a retrospective audit of consecutive patients who presented with a possible diagnosis of PMR between January 1999 and September 2010. Subjects were reviewed by rheumatologists in a tertiary outpatient clinic or private rheumatology practice. Some patients had been seen previously by their general practitioner or physician and had been diagnosed with PMR and commenced on steroids.

Patients were included if the diagnosis of PMR was considered at the initial clinical presentation. Two patients with a concomitant diagnosis of giant cell arteritis were excluded because of the higher steroid doses and longer duration of treatment required than for PMR alone, which would have potentially confounded analysis of the prednisone dosage. ${ }^{2,8}$

A pro forma data recording sheet generated by the authors was used as a framework for reviewing the clinical case notes. Subject characteristics of gender, age, symptom duration, and presence of other pre-existing rheumatic comorbidities were included. Antinuclear antibody, rheumatoid factor, and anticyclic citrullinated protein antibody status was also recorded. Other biochemical parameters used to assess disease activity were hemoglobin, C-reactive protein, and erythrocyte sedimentation rate. Biochemical markers and prednisone doses were assessed at the initial review, again at one month, and at 3, 6, and 12 months. Use of DMARDs was also noted.

Definition of response was based on the Polymyalgia Rheumatica Activity Score (PMR-AS), which takes into account the visual analog score for pain, visual analog score for physician's assessment, morning stiffness of the shoulder and hip girdles, ability to elevate the upper limbs, and inflammatory markers. ${ }^{21,22}$ Successful weaning and cessation of steroids was also incorporated into the definition used for remission. ${ }^{21,22}$ Patients were also monitored for development of other rheumatic conditions and malignancy.

\section{Results}

\section{Patient characteristics}

Between January 1999 and December 2010, a total of 137 consecutive patients presenting with polymyalgic 
symptoms were identified. Two patients were excluded because the final diagnosis included giant cell arteritis, leaving 135 patients (91 women and 44 men, mean age $70.7 \pm 9.5$ [44-89] years). Mean symptom duration prior to first presentation to their general practitioner, physician, or rheumatologist was 19.9 weeks, but after excluding outliers, this value decreased to $12.9 \pm 11.6$ weeks. On initial screening, 6.6\% were antinuclear antibody-positive and 6.6\% were rheumatoid factor-positive. Anticyclic citrullinated protein antibody status was checked in 53\% of patients, with $2.2 \%$ returning a positive result. In our cohort, all those who were anticyclic citrullinated protein-positive were subsequently diagnosed with rheumatoid arthritis. Forty-five subjects had also been previously diagnosed with osteoarthritis (see Table 1).

\section{Treatment}

The reviewing rheumatologist initiated treatment in most cases. All patients were initially treated with oral prednisone at a mean starting dose of 21.3 (range 8-60) mg. Figure 1 shows the subsequent tapering of prednisone during follow-up, indicating a mean dose of $5 \mathrm{mg}$ at the 12-month time point. We also reviewed the use of DMARDs as a steroid-sparing therapy for PMR, and found that these agents were used in $29.2 \%$ of patients and most often commenced after 3 months. The most commonly used agent was methotrexate, followed by sulfasalazine and hydroxychloroquine.

\section{Biochemical and clinical response}

In addition to various antibody tests, other hematological investigations ordered at the initial visit included markers of

Table I Subject characteristics

\begin{tabular}{ll}
\hline Gender & \\
Male, female (\%) & $32.8,67.2$ \\
Mean \pm SD age, years & $70.7 \pm 9.5$ \\
& $($ range $44-89)$ \\
Mean \pm SD symptom duration, weeks & $19.9 \pm 11.6$ \\
& $(12.9$ without outliers) \\
ANA-positive & $6.6 \%$ \\
Rheumatoid factor-positive & $6.6 \%$ \\
Anti-CCP antibody-positive & $2.2 \%$ \\
Number of patients with other pre-existing rheumatic comorbidities \\
Osteoarthritis & 45 \\
Gout & 3 \\
Rheumatoid arthritis & 3 \\
Psoriatic arthritis & 2 \\
Spinal stenosis & 3 \\
Paget's disease & 2 \\
\hline
\end{tabular}

Abbreviations: ANA, antinuclear antibody; SD, standard deviation; anti-CCP. anticyclic citrullinated protein. disease activity, such as hemoglobin, C-reactive protein, and erythrocyte sedimentation rate. The initial mean hemoglobin of $126 \mathrm{~g} / \mathrm{L}$ was in the lower range of the normal limit, and showed slight improvement following commencement of treatment to $133 \mathrm{~g} / \mathrm{L}$ at 3 months, and remaining stable at $134 \mathrm{~g} / \mathrm{L}$ and $132 \mathrm{~g} / \mathrm{L}$ at 6 and 12 months, respectively. Mean baseline C-reactive protein and erythrocyte sedimentation rate were $41.6 \mathrm{mg} / \mathrm{L}$ and $48.6 \mathrm{~mm}$ /hour, respectively. Only 16 patients did not have elevated inflammatory markers with a C-reactive protein $<10 \mathrm{mg} / \mathrm{L}$ and erythrocyte sedimentation rate $<40 \mathrm{~mm} /$ hour. Following the initiation of therapy, there was a marked decrease in both inflammatory markers, with mean C-reactive protein and erythrocyte sedimentation rate at 3 months normalizing to $8.6 \mathrm{mg} / \mathrm{L}$ and $14.6 \mathrm{~mm} /$ hour, respectively. This response was sustained throughout the 12-month follow-up period, as shown in Figures 2 and 3.

We also monitored liver function tests during treatment. At baseline, there were 75 (54.7\%) normal and 38 (27.8\%) abnormal liver function test results, with 24 (17.5\%) patients not tested. The most common abnormality during the follow-up period was mildly elevated alkaline phosphatase.

With regard to the clinical course of patients treated for polymyalgia, a clinical response was observed in $96.2 \%$ based on PMR-AS. Of these, 67\% showed a complete response and were asymptomatic, whilst 29\% showed a partial response. Patients who responded generally did so rapidly within days or weeks of initiating treatment. During the 12-month follow-up period, remission was achieved in only $18.2 \%$.

Among those diagnosed with definite PMR, multivariate analysis was used to examine the relationship between different variables and the clinical course of patients treated for polymyalgia, as summarized in Table 2. A complete clinical response was more likely with increasing age and in patients with negative antinuclear antibodies and negative rheumatoid factor status. Gender, symptom duration, and baseline inflammatory markers did not affect the clinical response. Remission was uncommon overall, and particularly so amongst the younger cohort ( $<1 \%$ for patients $<60$ years) and those with positive antinuclear antibodies and rheumatoid factor status, with remission rates of $1 \%$ and $0 \%$, respectively. Earlier presentation and treatment as measured by symptom duration was also predictive of remission. Fifteen percent of patients presenting within 10 weeks achieved remission. In contrast, only $7 \%$ achieved remission when presenting within 10-29 weeks of symptom onset, and no patients presenting at $\geq 30$ weeks showed remission. There was a trend towards poorer remission rates amongst those with a 


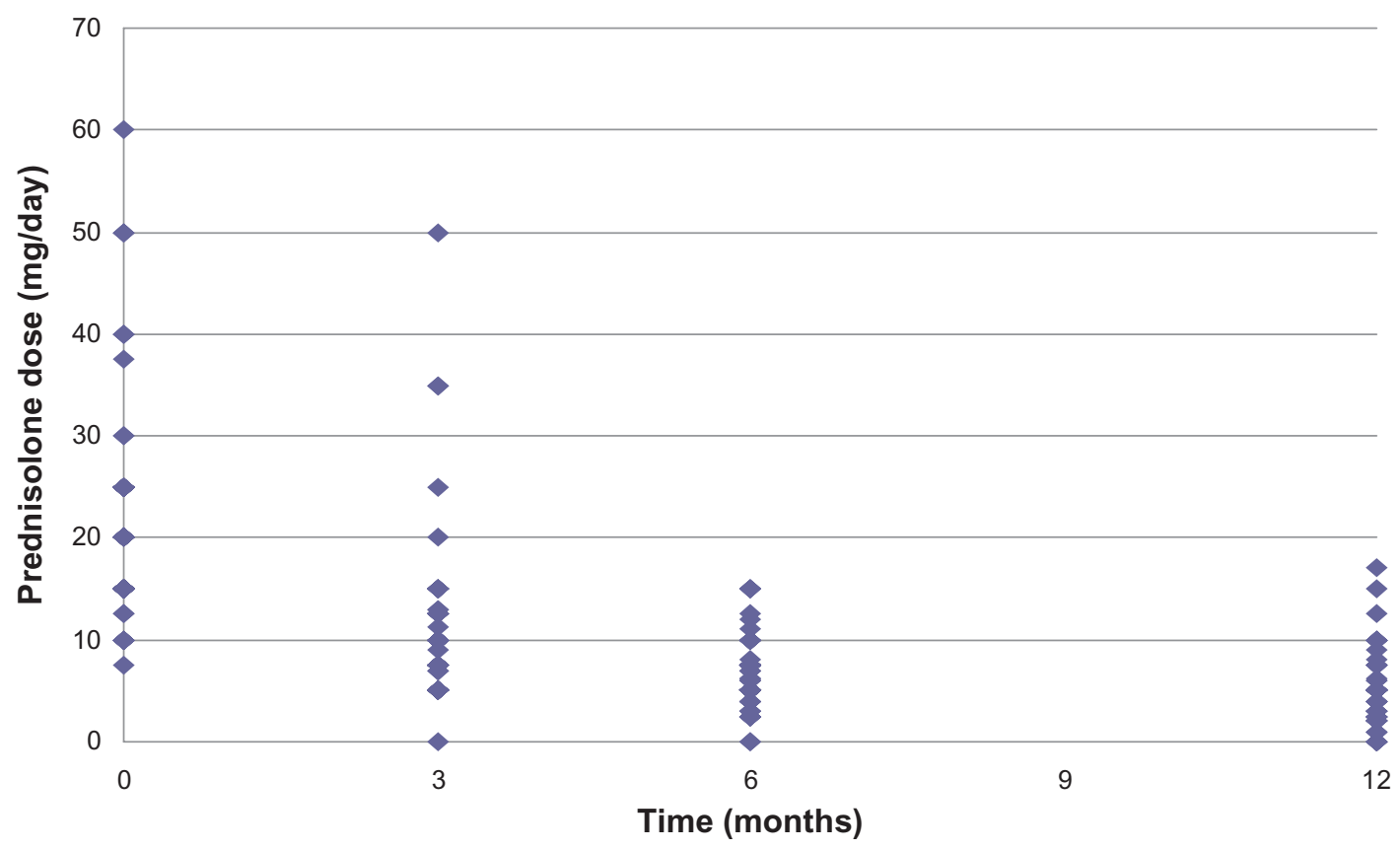

Figure I Prednisone dosing regimen.

higher baseline erythrocyte sedimentation rate, with levels of $<30 \mathrm{~mm} /$ hour and $\geq 70 \mathrm{~mm} /$ hour being associated with remission rates of $7 \%$ and $3 \%$, respectively. There was no correlation between baseline C-reactive protein levels and likelihood of remission.

\section{Associated diagnoses}

Of those initially diagnosed with PMR, 25.9\% were eventually diagnosed with a different rheumatic condition.
As shown in Figure 4, most of these patients $(n=18)$ were seronegative for rheumatoid arthritis. Giant cell arteritis was also recorded in two patients, equating to a prevalence of $1.5 \%$. These patients were excluded from the prednisone dosing analysis; they required maximum prednisone doses of $75 \mathrm{mg}$ and $80 \mathrm{mg}$, and did not show remission during the 12-month follow-up period.

Further analysis was performed comparing the subset of patients with definite PMR and those who were

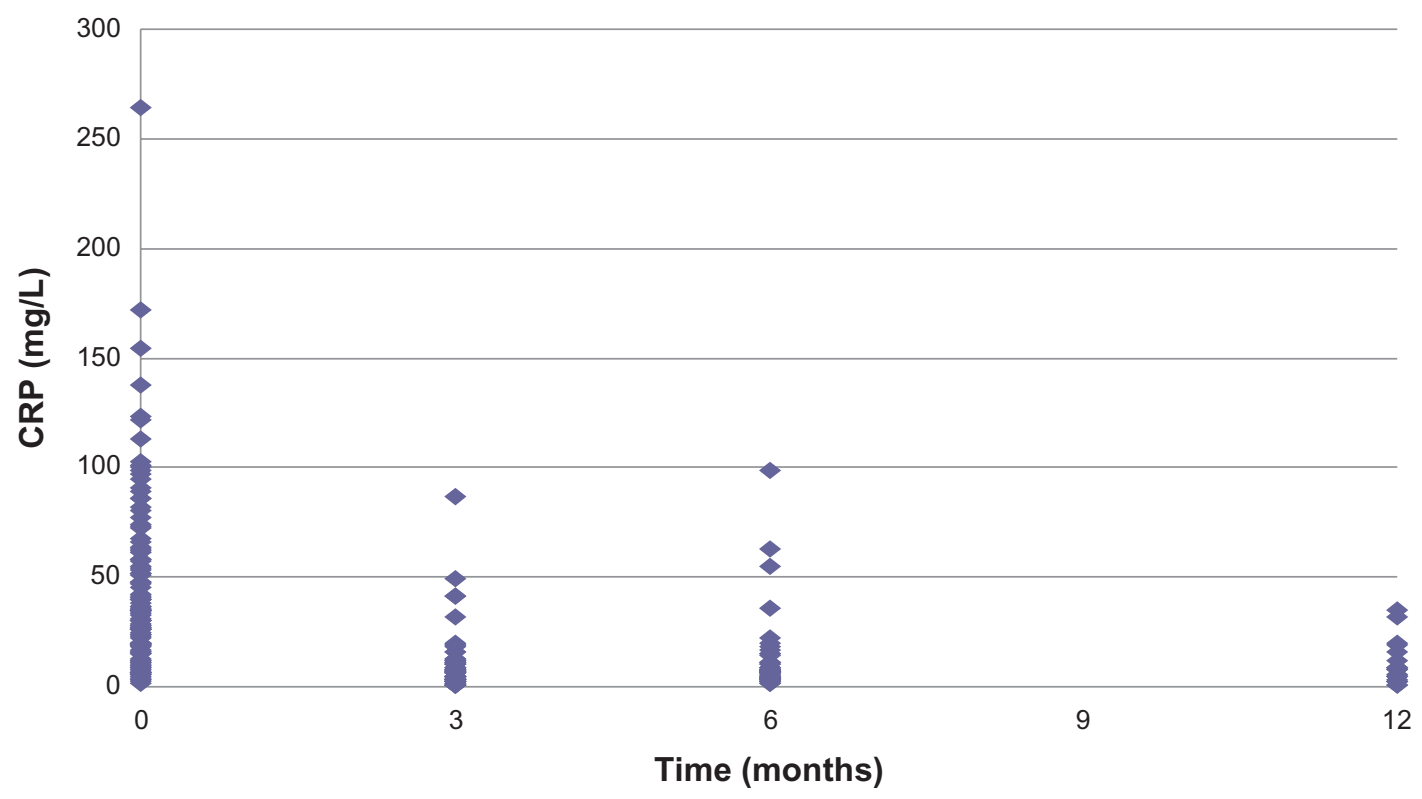

Figure 2 Trend of C-reactive protein during the treatment course. 


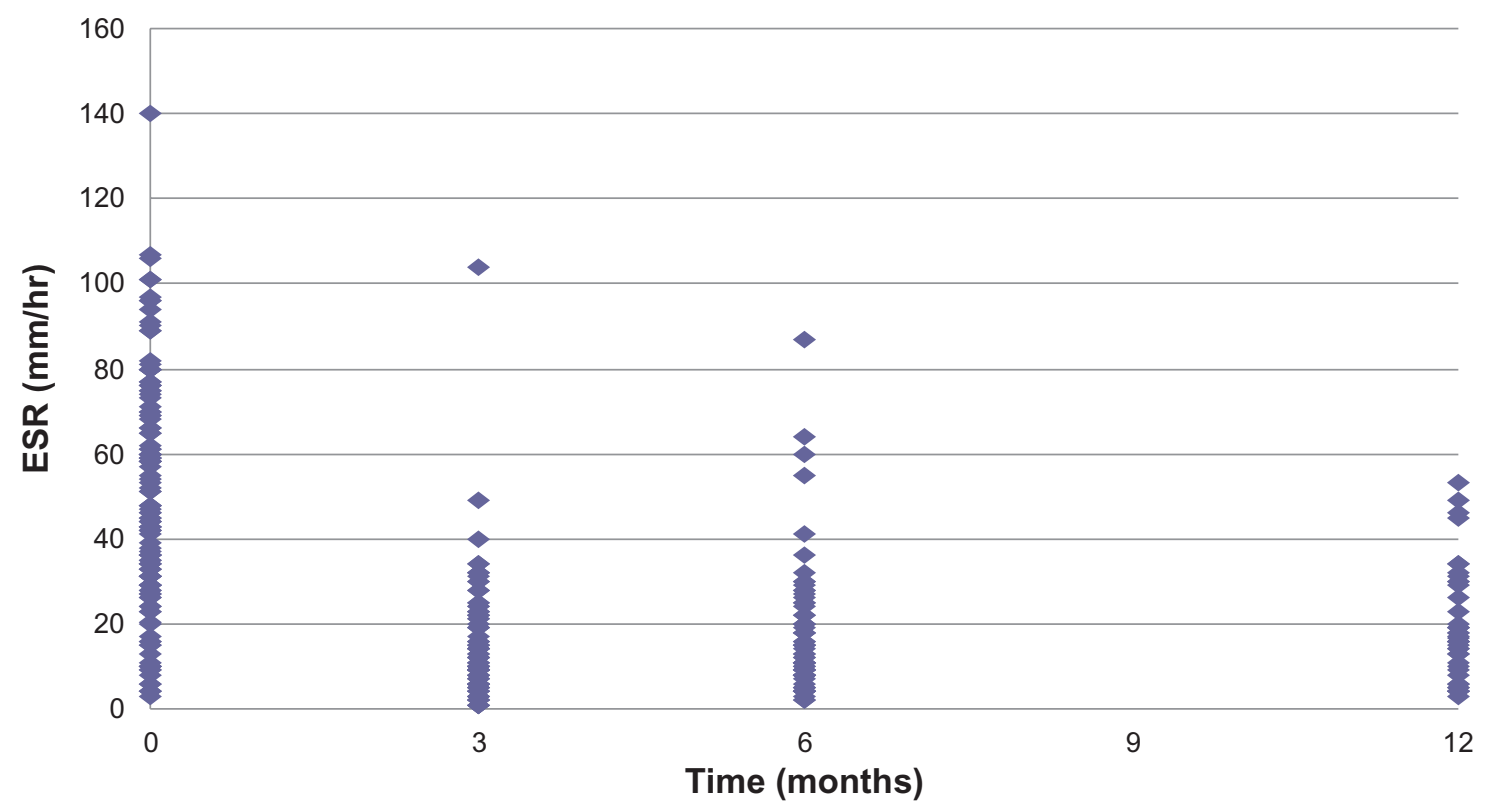

Figure 3 Trend of erythrocyte sedimentation rate during the treatment course. Abbreviation: ESR, erythrocyte sedimentation rate.

subsequently diagnosed with a different rheumatic condition. Those with definite PMR were older than those diagnosed with a different rheumatic condition (mean age 70.9 years versus 65.6 years, respectively). There was also a higher proportion of women than men in the definite PMR group ( $70 \%$ versus $56 \%$, respectively). The treatment course and biochemical patterns in each group are summarized in Table 3. The initial mean prednisone dose for both groups was similar, but those who were eventually diagnosed with another rheumatic condition generally required significantly higher prednisone doses $(P<0.05)$ and generally had higher levels of inflammatory markers (C-reactive protein and erythrocyte sedimentation rate) during the course of their disease, although this difference was not statistically significant $(P>0.05)$. As shown in Table 4 , a clinical response was evident in $99.0 \%$ of those with definite PMR compared with only $89 \%$ in those diagnosed with another rheumatic condition, whilst remission rates were $22 \%$ and $8 \%$, respectively.

Because there have been reports suggesting a possible relationship between PMR and underlying solid organ tumors and hematological malignancies, we also reviewed the case notes for such developments. In our audit, we observed only one case of monoclonal gammopathy of uncertain significance and one case of colorectal cancer.

\section{Discussion}

Because PMR is a condition that primarily affects the elderly population, it is not surprising that a large portion of our study cohort had other pre-existing rheumatic comorbidities (Figure 1). All those who were positive for anticyclic citrullinated protein were subsequently diagnosed with rheumatoid arthritis. Anticyclic citrullinated protein antibody status is increasingly being used to supplement rheumatoid factor status in the diagnosis of rheumatoid arthritis because it is equally sensitive $(62 \%-64 \%)$ but has a higher specificity of $97 \%$ compared with $90 \%$ for the latter. ${ }^{23}$

Both inflammatory markers (C-reactive protein and erythrocyte sedimentation rate) were elevated on initial screening in $87.7 \%$ of patients presenting with symptoms of polymyalgia, which is in keeping with diagnostic criteria. The exact role and value of testing for these inflammatory markers in prognostication has been investigated in the past, with inconclusive results. ${ }^{24}$ It has been proposed that an elevated erythrocyte sedimentation rate may be a more accurate predictor of prognosis, including the need for more prolonged steroid requirements and lower remission rates. In contrast, it is proposed that C-reactive protein levels may be more reflective of acute disease activity. ${ }^{24}$ Further, there has been research into the role of the proinflammatory cytokine, interleukin-6. Although interleukin-6 is still used primarily for research purposes, it is postulated that it is similar to C-reactive protein, in that it may be indicative of acute disease activity. ${ }^{24,25}$ The observed mildly elevated alkaline phosphatase is not uncommon, as documented in the literature, although the pathophysiological mechanism is not well understood. ${ }^{1,26}$ The significance of this finding is unclear, given the high proportion of incomplete follow-up data. 
Table 2 Multivariate analysis of the clinical course of patients treated for polymyalgia rheumatica in whom the diagnosis was confirmed

\begin{tabular}{|c|c|c|c|c|c|c|c|}
\hline & \multirow[t]{2}{*}{$\begin{array}{l}\text { Percentage of } \\
\text { patients overall }\end{array}$} & \multirow[t]{2}{*}{$\begin{array}{l}\text { Patients with } \\
\text { definite PMR 9n }\end{array}$} & \multicolumn{3}{|c|}{ Clinical response in those with definite PMR } & \multicolumn{2}{|c|}{$\begin{array}{l}\text { Remission in those with } \\
\text { definite PMR }\end{array}$} \\
\hline & & & No response & Partial response & Complete response & Not achieved & Achieved \\
\hline \multicolumn{8}{|l|}{ Gender } \\
\hline Female & 67.2 & 71 & $1 \%$ & $21 \%$ & $78 \%$ & $87 \%$ & $13 \%$ \\
\hline Male & 32.8 & 29 & $0 \%$ & $24 \%$ & $76 \%$ & $91 \%$ & $9 \%$ \\
\hline \multicolumn{8}{|c|}{ Age (years) } \\
\hline$<50$ & 1.5 & 2 & $50 \%$ & $0 \%$ & $50 \%$ & $100 \%$ & $0 \%$ \\
\hline $50-59$ & 10.4 & 9 & $0 \%$ & $33 \%$ & $67 \%$ & $99 \%$ & $1 \%$ \\
\hline $60-69$ & 29.6 & 23 & $0 \%$ & $26 \%$ & $74 \%$ & $92 \%$ & $8 \%$ \\
\hline 70-79 & 42.2 & 49 & $0 \%$ & $20 \%$ & $80 \%$ & $90 \%$ & $10 \%$ \\
\hline$\geq 80$ & 16.3 & 17 & $0 \%$ & $12 \%$ & $88 \%$ & $97 \%$ & $3 \%$ \\
\hline \multicolumn{8}{|c|}{ Symptom duration (weeks) } \\
\hline$<10$ & 55.2 & 57 & $0 \%$ & $25 \%$ & $75 \%$ & $85 \%$ & $15 \%$ \\
\hline $10-29$ & 35.4 & 36 & $3 \%$ & $19 \%$ & $78 \%$ & $93 \%$ & $7 \%$ \\
\hline$\geq 30$ & 9.4 & 7 & $0 \%$ & $29 \%$ & $71 \%$ & $100 \%$ & $0 \%$ \\
\hline \multicolumn{8}{|l|}{ ANA } \\
\hline Positive & 6.6 & 9 & $11 \%$ & $22 \%$ & $67 \%$ & $99 \%$ & $1 \%$ \\
\hline Negative & 93.4 & 91 & $0 \%$ & $15 \%$ & $85 \%$ & $79 \%$ & $21 \%$ \\
\hline \multicolumn{8}{|c|}{ Rheumatoid factor } \\
\hline Positive & 6.6 & 7 & $17 \%$ & $17 \%$ & $66 \%$ & $100 \%$ & $0 \%$ \\
\hline Negative & 93.4 & 93 & $0 \%$ & $19 \%$ & $81 \%$ & $78 \%$ & $22 \%$ \\
\hline \multicolumn{8}{|c|}{ Anti-CCP antibody } \\
\hline Positive & 2.2 & 0 & - & - & - & - & - \\
\hline Negative & 97.8 & 100 & $1 \%$ & $15 \%$ & $84 \%$ & $78 \%$ & $22 \%$ \\
\hline \multicolumn{8}{|c|}{ Baseline CRP (mg/L) } \\
\hline$<10$ & 17.5 & 18 & $7 \%$ & $14 \%$ & $79 \%$ & $95 \%$ & $5 \%$ \\
\hline $10-29$ & 28.3 & 29 & $0 \%$ & $19 \%$ & $81 \%$ & $93 \%$ & $7 \%$ \\
\hline $30-49$ & 22.5 & 20 & $0 \%$ & $17 \%$ & $83 \%$ & $95 \%$ & $5 \%$ \\
\hline$\geq 50$ & 31.7 & 33 & $0 \%$ & $28 \%$ & $72 \%$ & $95 \%$ & $5 \%$ \\
\hline \multicolumn{8}{|c|}{ Baseline ESR $(\mathrm{mm} / \mathrm{hr})$} \\
\hline$<30$ & 28.1 & 25 & $0 \%$ & $26 \%$ & $74 \%$ & $93 \%$ & $7 \%$ \\
\hline $30-49$ & 28.1 & 28 & $4 \%$ & $25 \%$ & $71 \%$ & $93 \%$ & $7 \%$ \\
\hline $50-69$ & 22.7 & 22 & $0 \%$ & $10 \%$ & $90 \%$ & $95 \%$ & $5 \%$ \\
\hline$\geq 70$ & 21.1 & 25 & $0 \%$ & $24 \%$ & $76 \%$ & $97 \%$ & $3 \%$ \\
\hline
\end{tabular}

Abbreviations: ANA, antinuclear antibody; CRP, C-reactive protein; ESR, erythrocyte sedimentation rate; anti-CCP, anticyclic citrullinated protein; PMR, polymyalgia rheumatica.

There was a high proportion of patients demonstrating a clinical response to treatment with prednisone. Based on the PMR-AS, 96.2\% showed a clinical response, which was generally rapid within days to weeks of initiation of treatment. This excellent response rate to corticosteroid therapy is well established in the literature and has frequently been included as a diagnostic criterion for PMR in various guidelines. ${ }^{1,2,10,11,16}$ In contrast, remission rates were relatively low, with only $18.2 \%$ achieving remission within the 12-month study period. Similarly, another recent retrospective audit reported a remission rate of $15.7 \%$ in patients with PMR. ${ }^{27}$ Such results are consistent with the current literature, which reports that relapse is frequent, with rates of up to $50 \%$ and the vast majority of PMR patients requiring corticosteroid therapy for a minimum of 2 years. ${ }^{18,28}$
The mainstay of treatment for polymyalgia is corticosteroids, usually oral prednisone. The audited initial prednisone dosing of $21.3 \mathrm{mg}$ is in keeping with various recommended guidelines, which suggest a starting dose of 15-25 mg. ${ }^{16-18}$ Numerous studies have investigated the effectiveness of steroid-sparing DMARD therapy in PMR and giant cell arteritis. Currently, the exact role of such therapy in the management of PMR is not well established, with conflicting results from various trials. ${ }^{10,16-18}$ Although most commonly used as steroid-sparing agents for steroiddependent patients in whom it is difficult to reduce the prednisone dose, it would be beneficial to investigate further their value when introduced early to induce remission, and whether they are effective in resistant cases of PMR. As such, there are no current guidelines for use of DMARDs 


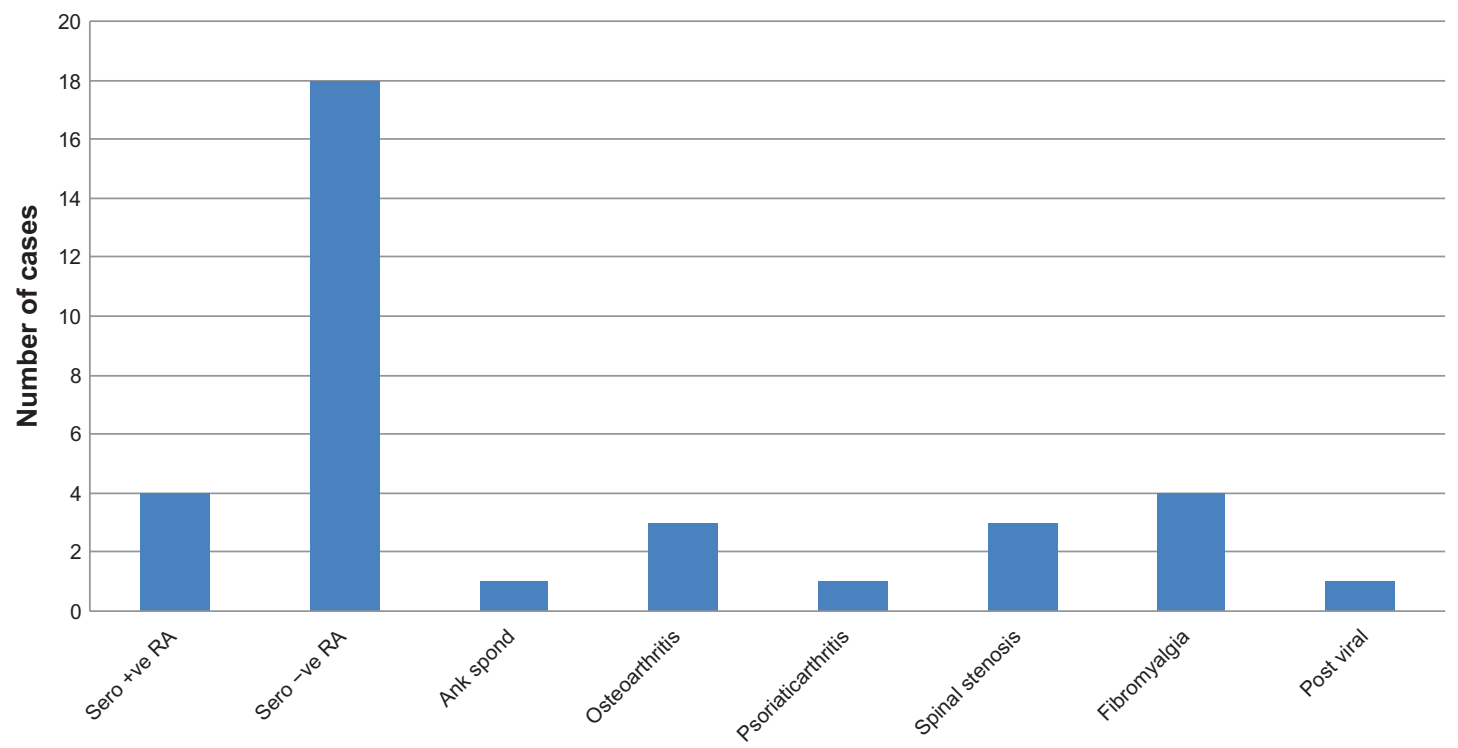

Figure 4 Number of cases with a final diagnosis other than polymyalgia rheumatica. Abbreviations: Ank Spond, ankylosing spondylosis; RA, rheumatoid arthritis.

in the treatment of PMR. Another emerging therapeutic strategy being trialed as a potential treatment for PMR is biologic agents, primarily the tumor necrosis factor antagonists, infliximab or etanercept. ${ }^{29-31}$ At present, only small case series including fewer than 50 patients have been reported. The results appear to be only modest, with etanercept being slightly more effective than infliximab in inducing remission as well as acting as a steroid-sparing agent. ${ }^{29-31}$ The benefits of biologic agents in the treatment

Table 3 Comparison of prednisone dosing and biochemical pattern between patients with definite PMR and those eventually diagnosed with another rheumatic condition

\begin{tabular}{|c|c|c|c|}
\hline & $\begin{array}{l}\text { Patients } \\
\text { diagnosed with } \\
\text { definite PMR } \\
(n=100)\end{array}$ & $\begin{array}{l}\text { Patients diagnosed } \\
\text { with another } \\
\text { rheumatic condition } \\
(n=35)\end{array}$ & $P$ value \\
\hline \multicolumn{4}{|c|}{ Mean prednisone dose (mg) } \\
\hline Initial review & 21.4 & 18.8 & 0.233 \\
\hline 3 months & 2.5 & 9.6 & $0.34 I$ \\
\hline 6 months & 2.5 & 7.4 & 0.045 \\
\hline 12 months & 3.75 & 6.3 & 0.021 \\
\hline \multicolumn{4}{|c|}{ Mean CRP (mg/L) } \\
\hline Initial review & 49.0 & 29.9 & 0.001 \\
\hline 3 months & 9.2 & 11.2 & 0.293 \\
\hline 6 months & 9.7 & 12.9 & 0.282 \\
\hline 12 months & 12.7 & 7.9 & 0.202 \\
\hline \multicolumn{4}{|c|}{ Mean ESR (mm/hour) } \\
\hline Initial review & 50.2 & 41.2 & 0.074 \\
\hline 3 months & 12.3 & 20.0 & 0.050 \\
\hline 6 months & 15.0 & 20.0 & 0.159 \\
\hline 12 months & 16.0 & 16.2 & $0.48 \mathrm{I}$ \\
\hline
\end{tabular}

Abbreviations: CRP, C-reactive protein; ESR, erythrocyte sedimentation rate; PMR, polymyalgia rheumatica. of temporal arteritis appear to be slightly more promising, but are again limited to small case series. ${ }^{31}$ Ultimately, the current value of DMARDs and biologic agents in the treatment of PMR appears uncertain, and further trials are needed to establish their precise role.

A large proportion of patients (25.9\%) presenting with polymyalgia were eventually diagnosed not with PMR but with another rheumatic disease, thus reflecting the broad differential diagnosis of polymyalgic symptoms. Further, this may represent a group of patients who present with PMR, which subsequently evolves into another rheumatic condition. ${ }^{8}$ It is reported that a diagnosis of concomitant giant cell arteritis is made in up to $20 \%$ of patients with PMR, but in our audit the prevalence was $1.5 \%{ }^{1,2}$ There are also reports linking PMR with solid organ tumors and hematological malignancy..$^{32}$ Although there may be an association, it was

Table 4 Comparison of clinical response between patients with definite PMR and those eventually diagnosed with another rheumatic condition

Patients diagnosed
with definite PMR
$(n=100)$

Patients diagnosed with another rheumatic condition $(n=35)$

\begin{tabular}{lll}
\hline Clinical response & & \\
Complete & $77 \%$ & $33 \%$ \\
Partial & $22 \%$ & $55 \%$ \\
No response & $1 \%$ & $12 \%$ \\
Clinical remission & & \\
Remission achieved & $22 \%$ & $8 \%$ \\
\hline
\end{tabular}

Abbreviation: PMR, polymyalgia rheumatica. 
not a significant one in this audit, possibly because of the limited sample size and relatively short follow-up period. It would be interesting to follow this cohort over a longer period to investigate any possible association between PMR and malignancy.

\section{Conclusion}

Symptoms of polymyalgia occur in patients with definite PMR and in those with other rheumatic conditions. The group of patients in our study had a good response to prednisone, although remission at the 12-month follow-up seemed to be uncommon. The gold standard of treatment for PMR remains corticosteroid therapy. However, due to the potential complications associated with long-term steroid treatment, an alternative means of treatment would be beneficial. The exact role and potential efficacy of steroid-sparing therapies, such as DMARDs and biologic agents, is as yet unclear. Further trials to establish the exact role of such therapies are needed.

\section{Acknowledgment}

The authors acknowledge Victoria Van and Nick Spendier for their contributions to the study design, data collection, and data analysis.

\section{Disclosure}

The authors report no conflicts of interest in this work.

\section{References}

1. Nothnagl T, Leeb BF. Diagnosis, differential diagnosis and treatment of polymyalgia rheumatica. Drugs Aging. 2004;23:391-402.

2. Inderjeeth C. Polymyalgia and giant cell arteritis. Med Today. 2009; 10:57-60.

3. Cimmino MA, Zaccaria A. Epidemiology of polymyalgia rheumatica. Clin Exp Rheumatol. 2000;18(4 Suppl 20):S9-S11.

4. Weyand CM, Hunder NN, Hicok KC, et al. HLA-DRB1 alleles in polymyalgia rheumatica, giant cell arteritis, and rheumatoid arthritis. Arthritis Rheum. 1994;37:514-520.

5. Wagner AD, Gerard HC, Fresemann T, et al. Detection of Chlamydia pneumoniae in giant cell vasculitis and correlation with the topographic arrangement of tissue-infiltrating dendritic cells. Arthritis Rheum. 2000;43:1543-1551.

6. Weyand CM, Hicok KC, Hunder GG, et al. Tissue cytokine patterns in patients with polymyalgia rheumatica and giant cell arteritis. Ann Intern Med. 1994;121:484-491.

7. Salvarani C, Cantini F, Hunder GG. Polymyalgia and giant-cell arteritis. Lancet. 2008;372:234-245.

8. Eamon M, Koening CL, Hoffman GS. Polymyalgia rheumatica and giant cell arteritis. Cleveland Clinic Online. Available from: http:// www.clevelandclinicmeded.com. Accessed March 10, 2011.

9. Dasgupta B, Matteson EL, Maradit-Kremers H. Management guidelines and outcome measures in polymyalgia rheumatica (PMR). Clin Exp Rheumatol. 2007;25:130-136.

10. Dasgupta B. Concise guidance: diagnosis and management of polymyalgia rheumatica. Clin Med. 2010;10:270-274.
11. Brooks RC, McGee SR. Diagnostic dilemmas in polymyalgia rheumatica. Arch Intern Med. 1997;157:162-168.

12. Cantini F, Niccoli L, Nannini C, et al. Inflammatory changes of hip synovial structures in polymyalgia rheumatica. Clin Exp Rheumatol. $2005 ; 23: 462-468$.

13. Frediani B, Falsetti P, Storri L, et al. Evidence for synovitis in active polymyalgia rheumatica: sonographic study in a large series of patients. J Rheumatol. 2002;29:123-130.

14. Salvarani C, Cantini F, Oliveri I, et al. Polymyalgia rheumatica: a disorder of extraarticular synovial structures? J Rheumatol. 1999;26:517-521.

15. Cantini F, Salvarani C, Olivieri I, et al. Shoulder ultrasonography in a diagnosis of polymyalgia rheumatica: a case-control study. J Rheumatol. 2001;28:1049-1055.

16. Hunder GG. Clinical manifestations and diagnosis of polymyalgia rheumatica. Up-to-Date Online. Available from: http://www.uptodate. $\mathrm{com} /$ contents/clinical-manifestations-and-diagnosis-of-polymyalgiarheumatica. Accessed March 10, 2013.

17. Gonzalez-Gay MA, Agudo M, Martinez-Dubois OP, et al. Medical management of polymyalgia rheumatica. Expert Opin Pharmacother. 2010;11:1077-1087.

18. Hernandez-Rodriguez J, Espigol-Frigole G. Treatment of polymyalgia rheumatica a systematic review. Arch Intern Med. 2009;169: 1839-1850.

19. Barnes TC, Daroszewska A, Fraser WD, et al. Bone turnover in untreated polymyalgia rheumatic. Rheumatology. 2004;43:486-490.

20. Caporali R, Cimmino MA, Ferracciolo G, et al. Prednisone plus methotrexate in polymyalgia rheumatica: a randomized, double-blind, placebo-controlled trial. Ann Intern Med. 2004;141:493-500.

21. Leeb BF, Rintelen B, Sautner J, et al. The Polymyalgia Rheumatica Activity Score in daily use: proposal for a definition of remission. Arthritis Rheum. 2007;57:810-815.

22. Leeb BF, Bird HA. A disease activity score for polymyalgia rheumatica. Ann Rheum Dis. 2004;63:1279-1283.

23. Silveira IG, Burlingame RW, Von Muhlen CA, et al. Anti-CCP antibodies have more diagnostic impact than rheumatoid factor (RF) in a population tested for RF. Clin Rheumatol. 2007;26:1883-1889.

24. Salvarani C, Cantini F, Niccoli L, et al. Acute-phase reactants and the risk of relapse/recurrence in polymyalgia rheumatica: a prospective followup study. Arthritis Rheum. 2005;53:33-38.

25. Corrigall VM, Dolan AL, Dasgupta B, et al. The sequential analysis of T lymphocyte subsets and interleukin-6 in polymyalgia rheumatica patients as predictors of disease remission and steroid withdrawal. $\mathrm{Br}$ J Rheumatol. 1997;36:976-980.

26. Hunder GG. Treatment of polymyalgia rheumatica. Up-to-Date Online. Available from: http://www.uptodate.com/contents/treatment-ofpolymyalgia-rheumatica. Accessed March 10, 2013.

27. Kim H, Lee J, Ha Y, et al. Induction of remission is difficult due to frequent relapse during tapering steroids in Korean patients with polymyalgia rheumatica. J Korean Med Sci. 2012;27:22-26.

28. Dejaco C, Duftner C, Cimmino MA, et al. Defnition of remission and relapse in polymyalgia rheumatica: data from a literature search compared with a Delphi-based expert consensus. Ann Rheum Dis. 2011;70:447-453.

29. Migliore A, Massafra U, Carloni E, et al. TNF-alpha blockade induce clinical remission in patients affected by polymyalgia rheumatic associated to diabetes mellitus and/or osteoporosis: a seven case report. Eur Rev Med Pharmacol Sci. 2005;9:373-378.

30. Salvarani $C$, Macchioni $P$, Manzini $C$, et al. Infliximab plus prednisone or placebo plus prednisone for the initial treatment of polymyalgia rheumatica: a randomized trial. Ann Intern Med. 2007;146:631-639.

31. Kreiner F, Galbo H. Effect of etanercept in polymyalgia rheumatica: a randomized controlled trial. Arthritis Res Ther. 2010;12:R176.

32. Rovensky J, Tuchynova A. Polymyalgia, temporal arteritis and occurrence of malignant tumours. Preliminary report of 26 patients with PMR and TA being followed prospectively. Cancer and Autoimmunity. 2000:81-83. 


\section{Publish your work in this journal}

Open Access Rheumatology Research and Reviews is an international peer-reviewed, open access journal, publishing all aspects of clinica and experimental rheumatology in the clinic and laboratory including the following topics: Pathology, pathophysiology of rheumatologica diseases; Investigation, treatment and management of rheumatological

Submit your manuscript here: http://www.dovepress.com/open-access-rheumatology-research-and-reviews-journa diseases; Clinical trials and novel pharmacological approaches for the treatment of rheumatological disorders. The manuscript management system is completely online and includes a very quick and fair peerreview system, which is all easy to use. Visit http://www.dovepress.com/ testimonials.php to read real quotes from published authors. 